\title{
MAPEAMENTO DE MANIFESTAÇÕES PATOLÓGICAS EM REVESTIMENTOS ARGAMASSADOS EXTERNOS DE EDIFÍCIOS DE MÚLTIPLOS PAVIMENTOS
}

\author{
Mapping of pathological manifestations in external harvested coverings of \\ multiple floor buildings
}

\author{
Amanda Menoti SILVA ${ }^{1}$, Cesar Fabiano FIORITI ${ }^{2}$
}

Recebido em 22 de janeiro de 2019; aceito em 09 de junho de 2019; disponível on-line em 12 de maio de 2020.

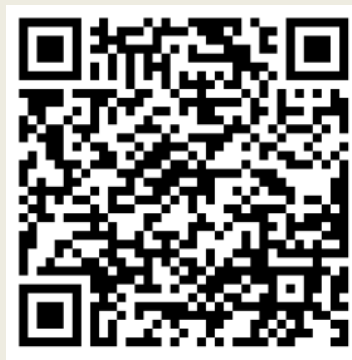

PALAVRAS CHAVE:

Problemas patológicos;

Anomalias;

Degradação;

Reboco;

Edifícios.

\section{KEYWORDS:}

Pathological problems;

Anomalies;

Degradation;

Plaster;

Buildings.

\footnotetext{
* Contato com os autores:

${ }^{1}$ e-mail: amandamenoti@gmail.com (A. M. Silva)

Arquiteta e Urbanista, foi Bolsista FAPESP de IC, Universidade Estadual Paulista - UNESP, Faculdade de Ciências e Tecnologia - FCT, Presidente Prudente - SP.

2e-mail: fioriti@fct.unesp.br (C. F. Fioriti )

Engenheiro Civil, Doutor, Professor Associado, Universidade Estadual Paulista - UNESP, Faculdade de Ciências e Tecnologia - FCT, Presidente Prudente - SP.
}

ABSTRACT: This paper aimed to mapping and analyze the pathological manifestations that interfere in the external mortar coverings of four residential buildings with multiple floors, located in the municipality of Presidente Prudente - SP - Brazil, as well as the identification of their probable causes, which allowed to recognize if the origins of the majority of the pathological problems arise from project failures or inaccuracies, plaster quality, failures of execution and, faults or failures of maintenance in structural systems and in constructive elements, during the use of these buildings. These results made it possible to classify the effects and causes of the anomalies identified in the external mortar coverings of the buildings, as well as to develop comparative tables for their analysis involving the effects, the probable origin and the influence of temperature and humidity on the causes of manifestations observed in buildings. In view of the above, the pathological manifestations in the mortar coatings studied were attributed to the negligence of actions and the non-consideration of aggressive agents, leading to the finding that the anomalies identified are due to omissions, lapses in detail and / or project interferences. Finally, this study contributes with data that serve as a warning to professionals in the area of civil construction. 


\section{INTRODUÇÃO}

Atualmente a construção civil vem convivendo com o surgimento de problemas patológicos em suas edificações, propiciados por distintos motivos. Para Mazer et al. (2016), a metodologia de avaliação proposto pela ASTM E632-82 (1996), que visa analisar a durabilidade das construções, apresenta variados agentes que acabam influenciando as edificações e podem ser isolados em cinco grupos diferenciados, conforme sua natureza: (1) atmosféricos, (2) biológicos, (3) de carregamentos, (4) de incompatibilidade e (5) de utilização.

Para Barros e Sabbatini (2001) as anomalias mais comumente encontradas nos revestimentos argamassados são: (a) as manchas oriundas de umidade, com posterior amplificação de microrganismo (bolor); (b) desplacamentos que surgem entre as faixas do reboco e emboço; e (c) constituição de trincas e fissuras.

Contudo, os fatores condicionados a ação atmosférica sobre as fachadas externas vem sendo amplamente estudados. Como apresenta o trabalho desenvolvido por Romero et al. (2011) que estudaram na Colômbia as fachadas da edificação denominada Torre Colpatria, e contemplaram a ocorrência de vários pontos com fissuras, carbonatação e ataque por sulfatos, relacionando os problemas patológicos constatados com a altura onde ocorreu a avaria, a orientação geográfica e o sentido prevalecente de chuvas e ventos.

Os autores Melo e Carasek (2014) estudaram fachadas de edifícios históricos e constataram a ocorrência de manchas propiciadas à ação microbiológica, sendo estas influenciadas por radiação solar. Os mesmos autores também relataram existir relação entre a direção predominante das chuvas com o surgimento de manchas.

No trabalho elaborado por Galletto e Andrello (2013), que também estudaram os revestimentos de fachadas de edifícios, foi observado que as fissuras, bem como as manchas e os descolamentos nos revestimentos de cerâmica, identificados em edificações atuais e envelhecidas, resultaram nas principais anomalias acometidas. Os citados autores também mencionaram que fissuras nos sistemas de rejuntamentos, possivelmente provenientes de intempéries, acabaram por influenciar no surgimento de outros danos constatados.

Melo e Carasek (2014) e Galletto e Andrello (2013), também estudaram a interferência de fatores ambientais, tais como: radiação solar, variação térmica, sentido predominante das chuvas e umidade na ocorrência de problemas patológicos, constatando que esses parâmetros são responsáveis pela geração incidente de anomalias em algumas das fachadas objeto de estudo.

Em Presidente Prudente, em função de vistorias realizadas, pode ser constatado que a maioria dos edifícios de múltiplos pavimentos foi executada com suas estruturas em concreto armado e fechamento com alvenaria de vedação, e consequente aplicação de revestimentos argamassados externos, sendo que a maior parte deles apresenta, pelo que foi observado, pouco controle das técnicas utilizadas no processo de execução.

Por fim, o principal desafio deste trabalho foi caracterizar, por meio de estudo de caso baseado em Silva (2007), a condição corrente das fachadas com revestimentos argamassados com ofício de substrato para revestimentos externos em quatro edifícios residenciais com múltiplos pavimentos em Presidente Prudente, com foco primordial as anomalias que atuam nas propriedades físicas do revestimento denominado reboco.

\section{OBJETIVO}

O trabalho teve como objetivo mapear e analisar as manifestações patológicas que atuam 
nos revestimentos argamassados externos de quatro edifícios residenciais dotados de múltiplos pavimentos, assim como a identificação de suas prováveis causas, o que permitiu reconhecer se as origens da maioria dos problemas patológicos identificados provêm de falhas ou indefinições de projetos, falhas de execução e, de falta ou falhas de manutenção durante o uso destes edifícios.

\section{BREVE REVISÃO BIBLIOGRÁFICA}

Conforme Silva (2007) os revestimentos argamassados estão sujeitos a ocorrência de vários fenômenos, dentre eles os ocasionados em função do meio ambiente, do projeto, da construção, das propriedades físicas e químicas dos componentes aplicados, do processo de manutenção, entre outros. No Quadro 1 pode-se ter o entendimento das manifestações patológicas encontradas nos revestimentos argamassados de fachadas.
Em função da extensão do assunto em questão, serão abordadas na sequência as manifestações patológicas com suprema ocorrência nos revestimentos argamassados de fachadas: as trincas e fissuras e a biodeterioração.

\subsection{TRINCAS E FISSURAS}

Segundo Corsini (2010), as fissuras se enquadram em um tipo considerado corrente de problema patológico nas edificações e podem interceder tanto na estética, como na durabilidade e nas particularidades estruturais da obra. A fissura pode ser originada em função da atuação de tensões nos materiais. Quando a solicitação acaba sendo mais elevada que a capacidade de resistência do material, a fissura tem a propensão de amenizar suas tensões. Desta maneira, quanto mais elevada for à restrição exigida a movimentação dos materiais, e quanto mais instável for, mais elevadas serão a gravidade e a veemência da fissura.

\begin{tabular}{|c|c|c|}
\hline Manifestação patológica & Efeitos & Causas prováveis \\
\hline Eflorescência & $\begin{array}{l}\text { - manchas de umidade } \\
\text { - pó branco acumulado na } \\
\text { superfície }\end{array}$ & $\begin{array}{l}\text { - umidade constante } \\
\text { - sais solúveis nas alvenarias e água de } \\
\text { amassamento }\end{array}$ \\
\hline $\begin{array}{l}\text { Bolor (fungos, algas, } \\
\text { liquens, etc.) }\end{array}$ & $\begin{array}{l}\text { - manchas esverdeadas, escuras } \\
\text { ou avermelhadas } \\
\text { - revestimento em desagregação }\end{array}$ & $\begin{array}{l}\text { - umidade constante } \\
\text { - área sem exposição ao sol }\end{array}$ \\
\hline Vesículas & $\begin{array}{l}\text { - empolamento da pintura } \\
\text { - bolhas com umidade }\end{array}$ & $\begin{array}{l}\text { - hidratação retardada da CaO (hidróxido } \\
\text { de cálcio/cor branca) } \\
\text { - pirita ou matéria orgânica na areia (cor } \\
\text { escura) } \\
\text { - concentrações ferruginosas na areia } \\
\text { - aplicação prematura de tinta } \\
\text { impermeável }\end{array}$ \\
\hline $\begin{array}{l}\text { Descolamento do reboco } \\
\text { com empolamento }\end{array}$ & $\begin{array}{l}\text { - descolamento do emboço } \\
\text { formando bolhas } \\
\text { - reboco com som cavo }\end{array}$ & $\begin{array}{l}\text { - infiltração de umidade } \\
\text { - hidratação retardada do MgO (hidróxido } \\
\text { de magnésio) }\end{array}$ \\
\hline \multirow[t]{2}{*}{$\begin{array}{l}\text { Descolamento do reboco } \\
\text { em placas }\end{array}$} & $\begin{array}{l}\text { - placa endurecida quebrando } \\
\text { com facilidade } \\
\text { - som cavo }\end{array}$ & $\begin{array}{l}\text { - placas frequentes de mica na camada } \\
\text { inferior } \\
\text { - argamassa muito rica ou muito espessa } \\
\text { - superfície com substâncias hidrófugas } \\
\text { - falta de aderência da superfície }\end{array}$ \\
\hline & $\begin{array}{l}\text { - placa endurecida e se } \\
\text { desagregando } \\
\text { - som cavo }\end{array}$ & $\begin{array}{l}\text { - argamassa magra } \\
\text { - ausência de chapisco }\end{array}$ \\
\hline Fissuras horizontais & $\begin{array}{l}\text { - ao longo da parede } \\
\text { - descolamento do revestimento } \\
\text { com som cavo }\end{array}$ & $\begin{array}{l}\text { - expansão da argamassa por hidratação } \\
\text { retardada do MgO } \\
\text { - expansão da argamassa por reação } \\
\text { cimento-sulfatos ou de argilo-minerais nos } \\
\text { agregados }\end{array}$ \\
\hline Fissuras mapeadas & $\begin{array}{l}\text { - forma variada e em toda a } \\
\text { superfície }\end{array}$ & - retração da argamassa de base \\
\hline
\end{tabular}


Este trabalho utilizou a classificação de trincas e fissuras de acordo Sabbatini e Barros (1990), que definem fissuras como as aberturas inferiores a 0,5mm de espessura, e trincas com medidas iguais ou maiores a $0,5 \mathrm{~mm}$. Porém, não há um consenso entre os estudiosos para uma classificação padrão da nomenclatura e das respectivas medidas referente às aberturas das fissuras.

Thomaz (1992) destacou as fissuras como sendo relevante devido a ocorrência de três aspectos: o alerta de alguma adversidade relevante na estrutura, o envolvimento do desempenho da obra em serviço e a imposição psicológica que a fissura exercita sobre os seus usuários.

Conforme Silva (2007), entre as principais anomalias que resultam da umidade da construção destacam-se as fissuras originadas no processo de retração de argamassa e concretos. Elas são ocasionadas, em sua maioria, por um controle menos rígido no desenvolvimento $e$ execução de cura dos materiais, gerando alterações irreversíveis.

Em seu estudo, Figueiredo (2003) empregou a seguinte classificação para apresentar a origem das fissuras nos revestimentos argamassados:

- Propiciadas por alterações de temperatura;

- Decorrentes de alterações do teor de umidade;

- Origem química;

- Propiciadas por ações mecânicas;

- Propiciadas por deformabilidade;

- Recalques diferenciais; e

- Propiciadas por falhas de projeto ou de execução.

\subsection{BIODETERIORAÇÃO}

O processo denominado deterioração de revestimentos externos pode ser dividido em fatores bióticos (fungos, algas e os liquens) e abióticos (umidade, temperatura, ventos, etc.).

Conforme Cincotto et al. (1995), tanto fungos, quanto algas e liquens acabam por desenvolver manchas de variadas colorações nas fachadas, causadoras de efeitos e aspectos não desejáveis e, em alguns casos, podendo prejudicar o revestimento superficial da edificação, posicionando o revestimento argamassado exposto diretamente às intempéries.

Para Cincotto (1988) pode-se denominar cientificamente como bolor as manchas resultantes do acúmulo de fungos filamentosos sobre um substrato qualquer. $\mathrm{O}$ agrupamento do bolor ocasiona o aparecimento de manchas de tonalidades escuras. Eventualmente surgem manchas claras e/ou esbranquiçadas, decorrentes de espécies mais incomuns.

Silva (2007) relatou que as consequências ocasionadas pela presença dos fungos são consideradas preocupantes, já que eles se alimentam, sobretudo, de materiais orgânicos retidos nas fachadas, algumas sujidades e do monóxido de carbono. Possuem também a capacidade de se alimentarem de alguns componentes existentes nas resinas de revestimentos superficiais, como por exemplo, os vernizes e as tintas, que são grandes concentradores de material orgânico nas suas respectivas composições, podendo ocasionar danos à película das tintas.

Segundo Freitas (2012), o mais importante fator abiótico refere-se à presença de umidade, sendo que estes organismos devem ser capazes de tolerar a falta de água. Para tanto, há duas formas, quais sejam, a estocagem de água para a manutenção dos processos biológicos em taxas normais, ou a tolerância à dessecação, caso dos microrganismos que se desenvolvem nas fachadas. Durante a dessecação, os processos biológicos são paralisados, mas eles podem ser rapidamente iniciados quando houver água disponível novamente.

Portanto, de acordo com Johansson (2006), a biodeterioração pode ser definida como uma mudança indesejada nas propriedades dos materiais, causada pela atividade de qualquer tipo de organismo. Os mecanismos envolvem a produção de ácidos, alteração da superfície, da absorção de calor e aumento da retenção de água. 


\section{METODOLOGIA}

A metodologia, baseada em Silva (2007), foi elaborada com o objetivo de orientar a coleta e a análise dos dados obtidos nas vistorias realizadas nos quatro edifícios residenciais com múltiplos pavimentos, objetos da amostra proposta para o trabalho. Dessa maneira, a metodologia foi detalhada em duas etapas como apresenta o texto na sequência.

\subsection{ETAPA 1: ANÁLISE DO ESTUDO DE CASO}

Serão apresentadas as fases que constituíram a etapa 1, baseada em Silva (2007):

a) Estudo da arte

Inicialmente foi realizado um levantamento bibliográfico sobre as generalidades das manifestações patológicas em revestimentos argamassados.

b) Critérios adotados para escolha do estudo de caso

Dentre as edificações, ficou estabelecido o universo dos edifícios residenciais com múltiplos pavimentos construídos nos últimos 30 anos. Deste universo, a triagem foi norteada pelos critérios a seguir: localização no perímetro urbano do município de Presidente Prudente - SP, constituídos com no mínimo três pavimentos, presença de manifestações patológicas nos revestimentos argamassados externos e executados com estrutura-suporte constituída de concreto armado.

\section{c) Edifícios selecionados}

Os edifícios selecionados para o estudo de caso estão localizados em bairros adjacentes ao Parque do Povo, uma área bem localizada, valorizada e consolidada no município, na qual é praticamente inexistente a presença de lotes vazios. 0 processo de seleção envolveu a escolha de quatro edifícios (Quadro 2). Para maior praticidade, eles foram doravante denominados de:

i. Edifício 1: composto por um pavimento térreo destinado à garagem e acesso, e outros três pavimentos tipo. São seis apartamentos no total, portanto, existem dois apartamentos residenciais em cada andar. Ele foi finalizado no ano de 1996; ii. Edifício 2: foi finalizado em 1997. No andar térreo encontra-se a garagem, sala de correspondências e os acessos para os quatro pisos superiores. São dezesseis apartamentos no total, sendo quatro unidades por andar;

iii. Edifício 3: foi finalizado em 1990. Possui um pavimento no subsolo e dezessete acima, sendo um total de sessenta e um apartamentos divididos em uma unidade no 10 andar e quatro unidades por andar, do 20 ao 16 pavimento;

iv. Edifício 4: foi finalizado em 1997, é composto por dois subsolos, andar térreo, mezanino, quinze pavimentos tipo e cobertura.

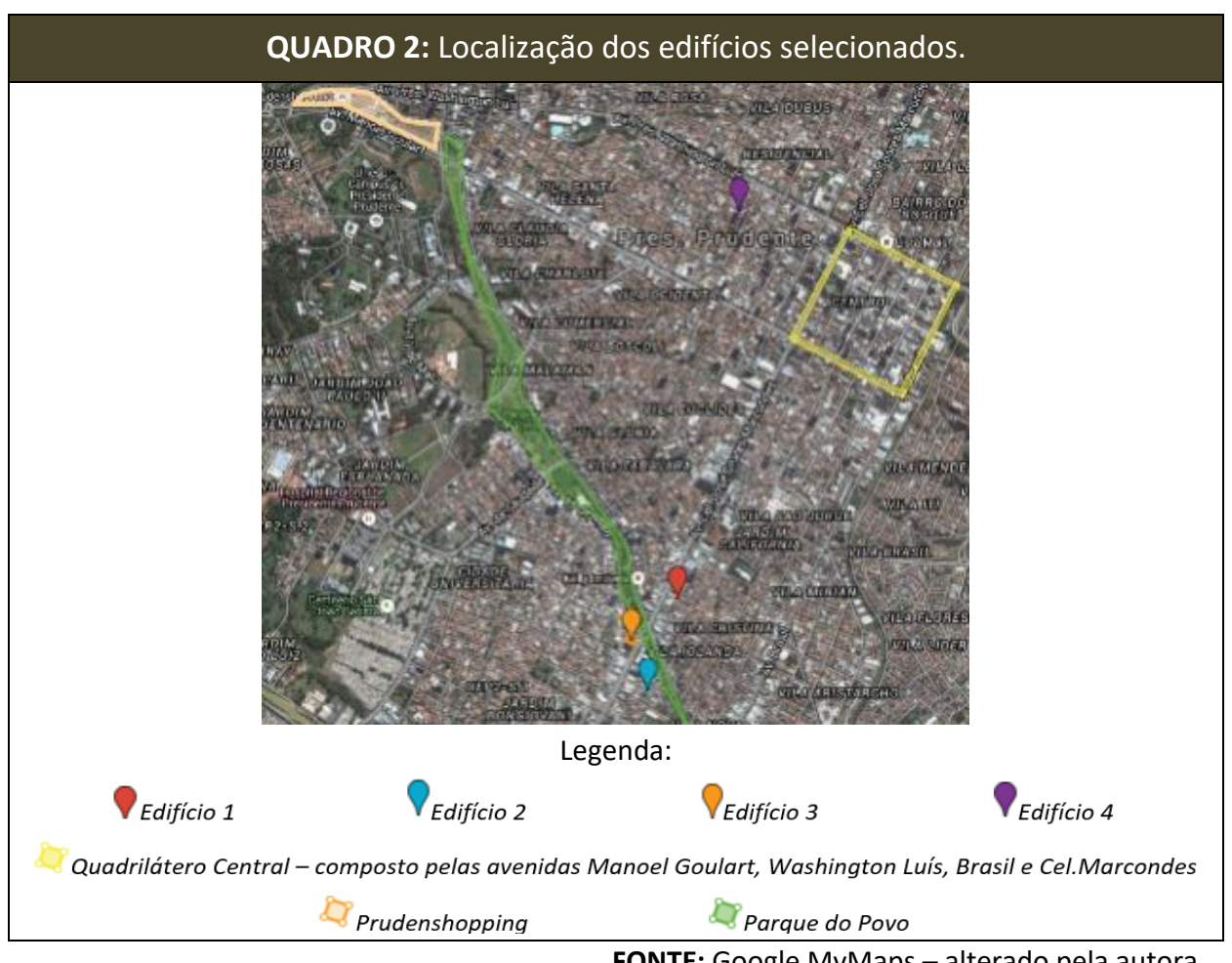

FONTE: Google MyMaps - alterado pela autora. 


\section{d) Coleta das informações}

As primeiras informações necessárias para a elaboração do trabalho foram obtidas por meio de inspeção visual e por levantamentos buscando dados sobre o histórico dos edifícios. Também foram obtidos os projetos arquitetônicos de todos os edifícios. Para o registro dos dados foi utilizada a seguinte sistematização:

- localização: situação e orientação solar;

- descrição do edifício: data da conclusão da obra, descrição do sistema construtivo, material de revestimento, quantidade e sistema de manutenções (quando houver);

- documentação: projetos de arquitetura;

- características do projeto: área construída, forma arquitetônica, técnicas construtivas, materiais utilizados, fachadas, cores, etc.;

- registro e descrição das manifestações patológicas: fotos e descrição das anomalias identificadas.

Adianta-se, desde já, que foi omitido nesse trabalho o nome de síndicos e de moradores colaboradores, bem como a identificação de todos os envolvidos na construção dos edifícios que compõem as amostras estudadas, devido à natureza do trabalho.

e) Registro e descrição das manifestações patológicas dos edifícios

Apresentação do registro das manifestações patológicas por meio de fotos produzidas durante as vistorias dos edifícios estudados. Cabe mencionar que foi realizada em todas as fachadas dos edifícios uma verificação percutida de modo a verificar a ocorrência de pontos em processo de destacamento.

\subsection{ETAPA 2: ANÁLISE DOS RESULTADOS}

Apresentação da análise das manifestações patológicas no estudo de caso, que foram desenvolvidas baseadas em Silva (2007), por meio de: efeitos ocorridos nos revestimentos argamassados externos, causas dos problemas patológicos nos revestimentos argamassados externos, origens dos problemas patológicos dos revestimentos argamassados externos, interferência da temperatura e da umidade nas causas das manifestações patológicas identificadas nos edifícios.

\section{RESULTADOS E ANÁLISE}

\subsection{MANIFESTAÇÕES IDENTIFICADAS}

PATOLÓGICAS

Conforme os dados levantados em campo, as manifestações patológicas mais recorrentes nas fachadas do Edifício 1 foram provenientes de fissuras, sujidades, destacamentos da pintura e destacamentos de revestimento. Nas fachadas do Edifício 2 foram identificados esfarelamentos, bolhas na pintura, fissuras, destacamentos da pintura, manchas, sujidades e vegetações crescentes. No Edifício 3 foram identificados destacamentos da pintura, fissuras e manchas. O Edifício 4 foi acometido por destacamentos da pintura, fissuras, manchas de corrosão e destacamento do revestimento com exposição de armadura. A seguir o Quadro 3 apresenta algumas das anomalias observadas nos edifícios.

\subsection{EFEITOS OCORRIDOS NOS REVESTIMENTOS DAS FACHADAS}

A avaliação dos efeitos que as manifestações patológicas provocaram nas fachadas argamassadas dos edifícios possibilitou relacionar os tipos de efeitos e verificar a proporção em que ocorreram, conforme mostram os Quadros 4, 5, 6 e 7.

Com base nos quadros apresentados foi possível criar um quantitativo quanto ao número de aparições de cada efeito. A fissuração do revestimento foi o efeito que apareceu em maior proporção e está presente em 10 manifestações patológicas; em seguida está o destacamento da pintura, notado em 7 anomalias; em menor proporção está o destacamento do revestimento, presente em 6 casos; a presença de microrganismos e manchas escuras apareceram em 5 anomalias, enquanto que a fissuração da pintura e o substrato aparente apareceram em 4; as sujidades apareceram em apenas duas anomalias e a presença de vegetação, bolhas e elevada retenção de água foram notadas em apenas uma anomalia cada. 


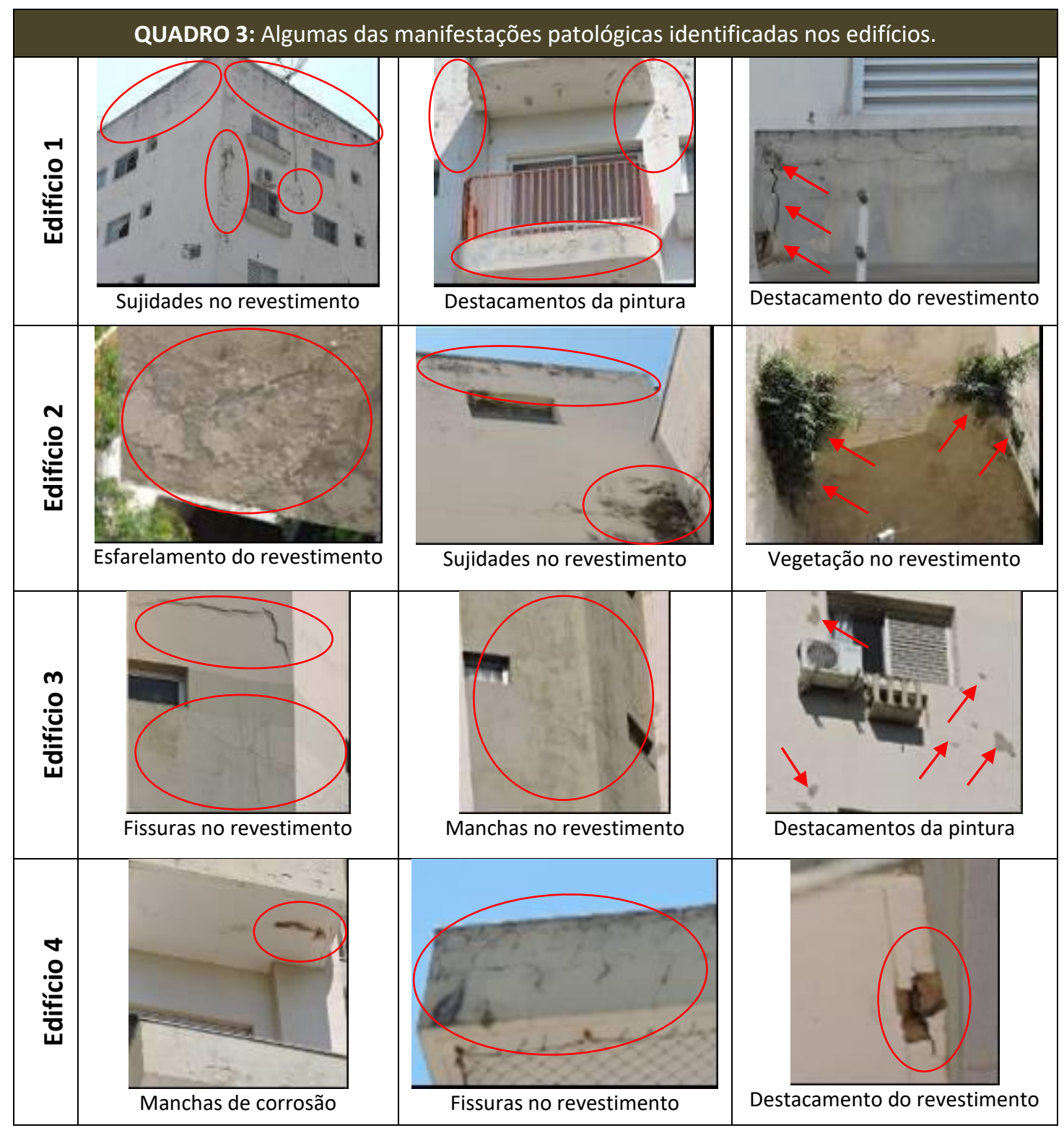

FONTE: Autoria própria.

\begin{tabular}{|c|c|c|c|c|c|}
\hline & QUADRO 4: Edifício 1 - Anomalia. & $1 \mathrm{~A}$ & 1B & 1C & 1D \\
\hline \multirow{7}{*}{ 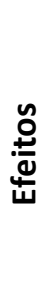 } & Destacamento do revestimento & & & & \\
\hline & Destacamento da pintura & & & & \\
\hline & Fissuração do revestimento & & & & \\
\hline & Substrato aparente & & & & \\
\hline & Presença de microrganismos & & & & \\
\hline & Sujidades & & & & \\
\hline & Manchas escuras & & & & \\
\hline
\end{tabular}

FONTE: Autoria própria. 


\begin{tabular}{|c|c|c|c|c|c|c|c|c|}
\hline & QUADRO 5: Edifício 2 - Anomalia. & $2 A$ & 2B & $2 \mathrm{C}$ & 2D & 2E & $2 F$ & 2G \\
\hline \multirow{12}{*}{$\begin{array}{l}\stackrel{n}{\circ} \\
\stackrel{+}{d} \\
\frac{4}{4}\end{array}$} & Destacamento do revestimento & & & & & & & \\
\hline & Destacamento da pintura & & & & & & & \\
\hline & Fissuração da pintura & & & & & & & \\
\hline & Fissuração do revestimento & & & & & & & \\
\hline & Substrato aparente & & & & & & & \\
\hline & Presença de microrganismos & & & & & & & \\
\hline & Presença de vegetação & & & & & & & \\
\hline & Sujidades & & & & & & & \\
\hline & Presença de bolhas & & & & & & & \\
\hline & Manchas escuras & & & & & & & \\
\hline & Esfarelamento do revestimento & & & & & & & \\
\hline & Elevada Retenção de água & & & & & & & \\
\hline
\end{tabular}

FONTE: Autoria própria.

\begin{tabular}{|c|c|c|c|c|}
\hline & QUADRO 6: Edifício 3 - Anomalia. & 3A & 3B & $3 C$ \\
\hline \multirow{5}{*}{ 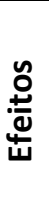 } & Destacamento da pintura & & & \\
\hline & Fissuração da pintura & & & \\
\hline & Fissuração do revestimento & & & \\
\hline & Substrato aparente & & & \\
\hline & Manchas escuras & & & \\
\hline
\end{tabular}

FONTE: Autoria própria.

\begin{tabular}{|c|c|c|c|c|c|}
\hline & QUADRO 7: Edifício 4 - Anomalia. & $4 A$ & 4B & $4 C$ & 4D \\
\hline \multirow{7}{*}{ 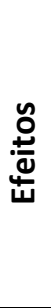 } & Destacamento do revestimento & & & & \\
\hline & Destacamento da pintura & & & & \\
\hline & Fissuração da pintura & & & & \\
\hline & Fissuração do revestimento & & & & \\
\hline & Manchas marrom-avermelhada & & & & \\
\hline & Substrato aparente & & & & \\
\hline & Presença de microrganismos & & & & \\
\hline
\end{tabular}

FONTE: Autoria própria.

\subsection{PROVÁVEIS ORIGENS DAS MANIFESTAÇÕES PATOLÓGICAS}

A avaliação das prováveis origens que provocaram os efeitos encontrados nas fachadas dos edifícios possibilitou desenvolver os Quadros $8,9,10$ e 11, que identificam a motivação que desencadeou cada manifestação patológica.

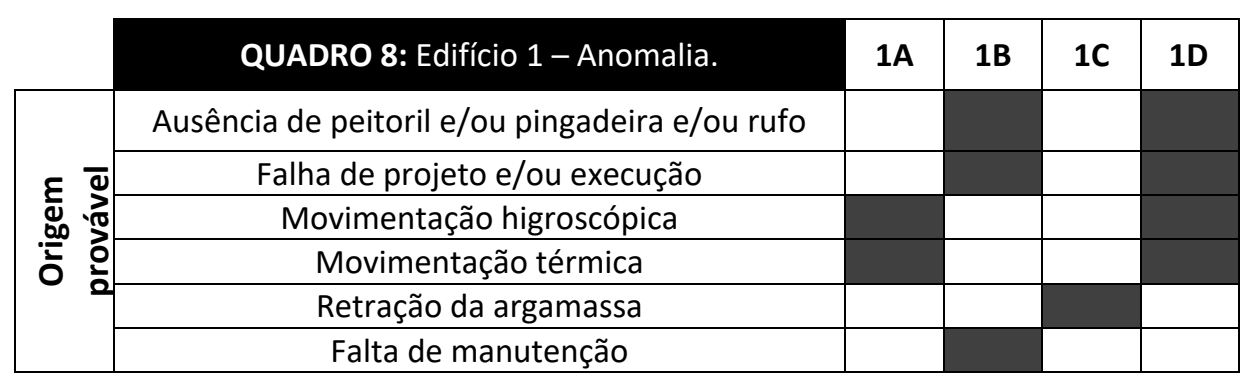

FONTE: Autoria própria. 


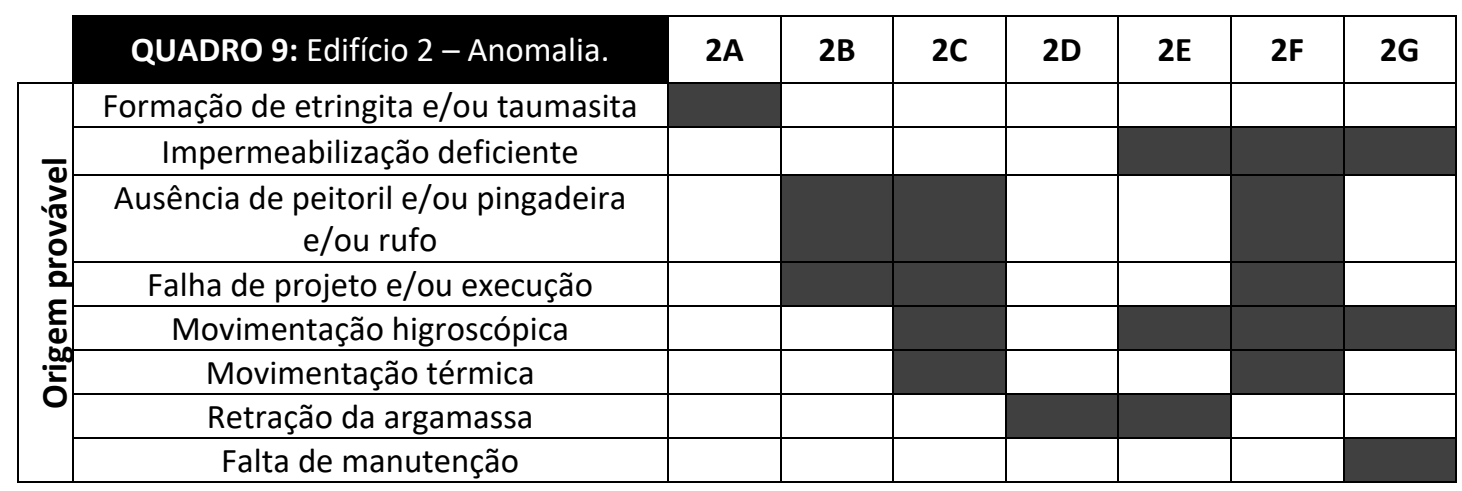

FONTE: Autoria própria.

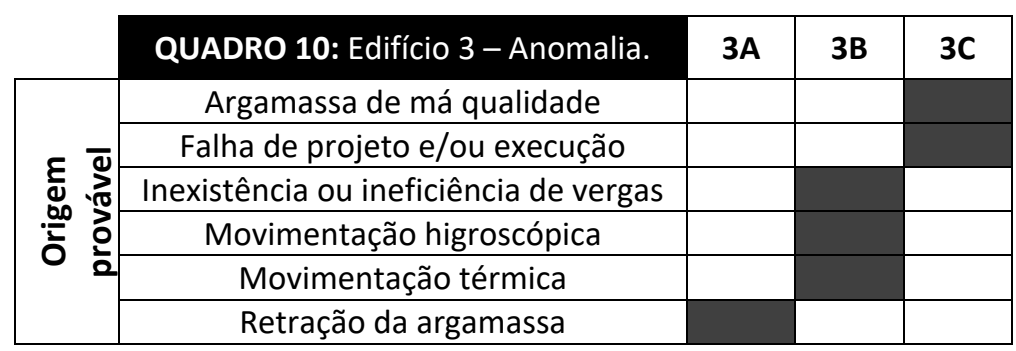

FONTE: Autoria própria.

\begin{tabular}{|c|c|c|c|c|c|}
\hline & QUADRO 11: Edifício 4 - Anomalia. & 4A & 4B & 4C & 4D \\
\hline \multirow{7}{*}{ 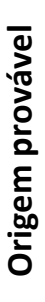 } & Corrosão da armadura & & & & \\
\hline & Impermeabilização deficiente & & & & \\
\hline & Falha de projeto e/ou execução & & & & \\
\hline & Inexistência ou ineficiência de vergas & & & & \\
\hline & Movimentação higroscópica & & & & \\
\hline & Movimentação térmica & & & & \\
\hline & Retração da argamassa & & & & \\
\hline
\end{tabular}

FONTE: Autoria própria.

Conforme os resultados de origem das manifestações patológicas apresentados nos Quadros 8 a 11, foi possível criar um quantitativo quanto ao número de aparições de cada possível origem. A falha de projeto e/ou execução e as movimentações higroscópicas foram as prováveis origens que apareceram com maior frequência, totalizando 8 anomalias em que elas estão presentes; em seguida estão a ausência de peitoril e/ou pingadeira e/ou rufo e as movimentações térmicas, que aparecem em 6 casos cada uma; a retração da argamassa é citada 5 vezes, a impermeabilização deficiente é citada 4 vezes, e a falta de manutenção, corrosão da armadura e inexistência ou ineficiência de vergas aparecem como provável origem 2 vezes; a formação de etringita e/ou taumasita e argamassa de má qualidade e estão presentes em apenas uma anomalia cada.

\subsection{ANÁLISE DA INCIDÊNCIA SOLAR}

A fim de melhor entender a influência da incidência solar sobre as anomalias observadas, será apresentado o Quadro 12 que contempla as respectivas cartas solares de cada edifício objeto de estudo.

Ao analisar a influência da incidência solar sobre a evolução das manifestações patológicas dos edifícios estudados, podem ser notados dois tipos de influência: a que inibe e a que promove a evolução das anomalias. 


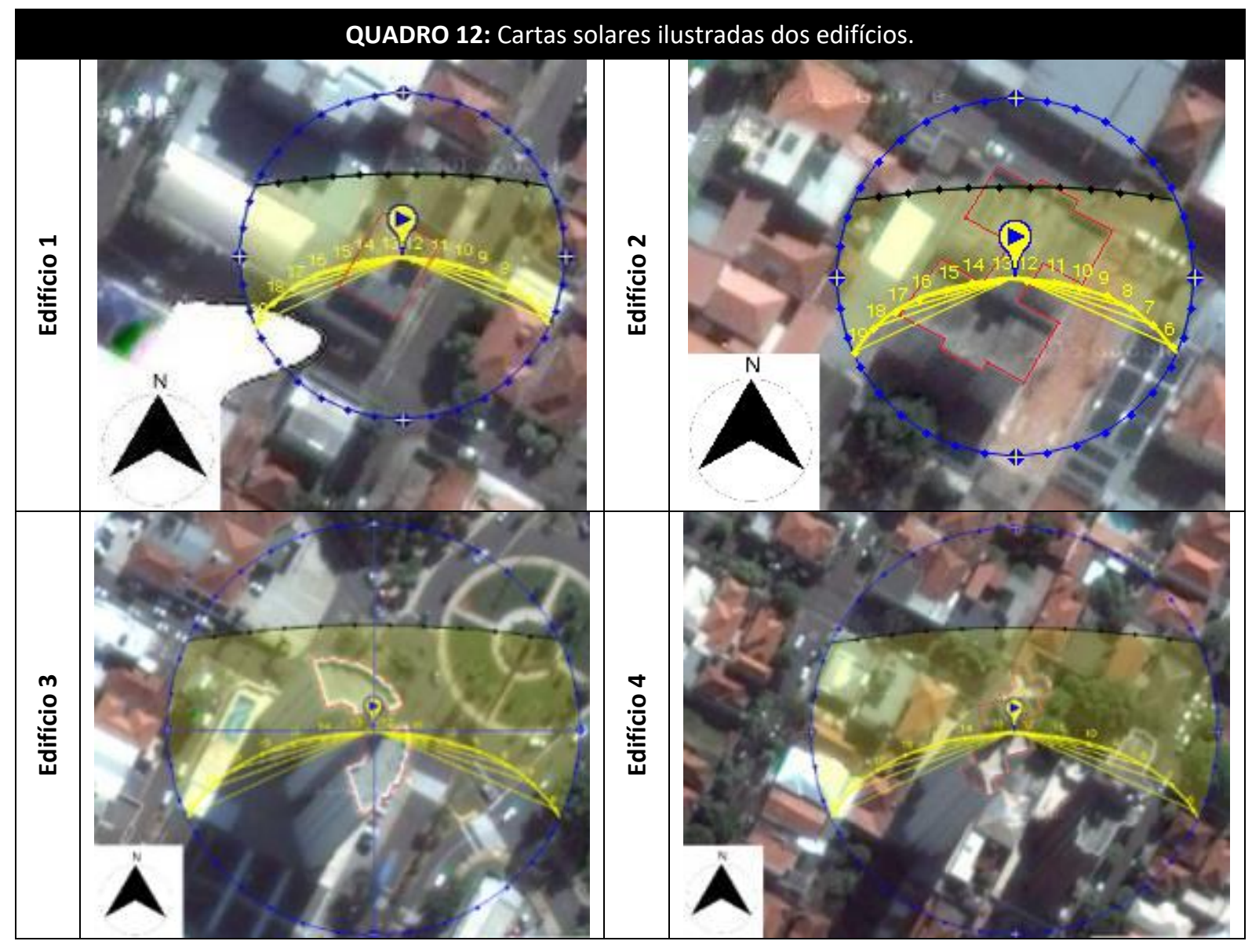

FONTE: Autoria própria.

No Edifício 1, a insolação contribuiu para a inibição da proliferação de microrganismos e evolução de manchas e sujidades. Tais anomalias são favorecidas por umidade e sombra, e a incidência direta dos raios solares tornou as fachadas pouco favoráveis para esse tipo de manifestação patológica.

Nos Edifícios 2, 3 e 4 a insolação levou à promoção da evolução das manifestações patológicas. As altas temperaturas favoreceram a movimentação térmica dos revestimentos argamassados das fachadas, fator que permitiu a evolução das anomalias encontradas nesses edifícios, tais como fissuração do revestimento e/ou da camada de pintura e destacamento do revestimento e/ou da camada de pintura.

\section{CONCLUSÕES}

Os Edifícios 1 e 2 são caracterizados de padrão inferior aos Edifícios 3 e 4, e isso é refletido no estado de preservação dos mesmos. Os dois últimos, visivelmente, realizam manutenções periódicas ao menos na parte externa dos edifícios - não houve acesso ao interior para conhecer as condições internas dos mesmos -, pois o padrão exige cuidado com a estética. Desse modo, as anomalias encontradas possuem severidade significativamente inferiores às encontradas nos primeiros prédios (Edifícios 1 e 2), que possuem revestimentos em estado mais avançado de deterioração e com ausência de sinais de manutenção recente.

Diante do exposto, as manifestações patológicas nos revestimentos argamassados estudados foram concedidas ao desatento de ações e a não consideração de agentes agressivos, levando a constatação de que as anomalias identificadas são provenientes de omissões, lapsos no detalhamento e/ou intercessão de projetos. Por fim, este estudo contribui com dados que servem de alerta aos profissionais da área de construção civil. 


\section{AGRADECIMENTO}

A FAPESP - Fundação de Amparo a Pesquisa do Estado de São Paulo, pela concessão da bolsa de iniciação científica a autora pelo período de dois anos.

\section{REFERÊNCIAS BIBLIOGRÁFICAS}

AMERICAN SOCIETY FOR TESTING AND MATERIALS. ASTM - E 632-82: Standard recommended practice for developing short-term accelerated test for prediction of the service life of building components and materials. Philadelphia, EUA, 1996.

BARROS, M. M. S. B., SABBATINI, F. H. Produção de revestimentos cerâmicos para paredes de vedação em alvenaria: diretrizes básicas. São Paulo, Brasil: EPUSP, 2001.

CINCOTTO, M. A. Patologia das argamassas de revestimento: análise e recomendações. In: Tecnologia das Edificações. São Paulo, Brasil: Pini/IPT, 1988.

CINCOTTO, M. A., SILVA, M. A. C., CARASEK, H. Argamassas de revestimento; características, propriedades e métodos de ensaio. Publicação IPT 2378. 1. ed. São Paulo: Instituto de Pesquisas Tecnológicas, 118p., 1995.

CORSINI, R. Trinca ou fissura? Revista de Tecnologia da Construção - Téchne, 2010. Disponível em: <http://www.revistatechne.com.br/engenhariacivil/160/trinca-ou-fissura-como-seoriginam-quais-ostipos-179241-1.asp>. Acesso em 23/06/2017.

FIGUEIREDO, A. C. Proposta de metodologia para estudo de patologias nas edificações do CTA. Trabalho de Conclusão de Curso (Graduação) - Instituto Tecnológico de Aeronáutica, ITA, São José dos Campos, SP, 2003

FREITAS, J. G. A influência das condições climáticas na durabilidade dos revestimentos de fachada: estudo de caso na cidade de Goiânia-GO. Dissertação (Mestrado) - Universidade Federal de Goiás, UFG, Goiânia, GO, 2012.

GALLETTO, A., ANDRELLO, J. M. Patologia em fachadas com revestimentos cerâmicos. In: CINPAR - IX Congresso Internacional sobre Patologia e Recuperação de Estruturas. João Pessoa/PB), 2013.
JOHANSSON, S. Biological growthon mineral façades. Tese (Doutorado) - Lund University, Lund, Suécia, 2006.

MAZER, W., SILVA, L. M. R., LUCAS, E., SANTOS, F. C. M. Avaliação de manifestações patológicas em edifícios em função da orientação geográfica. Revista ALCONPAT. Vol. 6, no 2, pp. 145-156, 2016.

MELO, C. M., CARASEK, H. Relationship between the deterioration of multi story building facades and driving rain. Revista de la Construción. Vol. 13, no 1, pp. 64-73, 2014.

ROMERO, N., DUPUY, C., QUIÑONES, J. Influência de la contaminación atmosférica em la fachada de rascacielos, caso Torre Colpatria. Revista ALCONPAT. Vol. 1, no. 3, pp. 228-235, 2011.

SABBATINI, F. H., BARROS, M. M. S. B. Recomendações para produção de revestimento cerâmicos para paredes de vedação em alvenaria. São Paulo, Convênio EPUSP/CqDCC, 1990.

SILVA, A. F. Manifestações patológicas em fachadas com revestimentos argamassados: Estudo de caso em edifícios em Florianópolis. Dissertação (Mestrado) Universidade Federal de Santa Catarina, UFSC, Florianópolis, SC, 2007.

THOMAZ, E. Trincas em edifícios: causas, prevenção e recuperação. São Paulo, Ed. PINI, 1992. 